\title{
Hinweise zur Wiedergabe von Personen- und Ortsnamen
}

Das hier angewandte System zur Wiedergabe von Personen- und Ortsnamen erhebt weder Anspruch auf Allgemeingültigkeit noch auf vollständige Konsistenz, da es für die Übertragung aus den jeweiligen Fremdsprachen keine einheitlich gebrauchten Regeln gibt. Oberstes Ziel der nachfolgend umrissenen Festlegungen ist es, das Wiederfinden aller verwendeten Orts- und Personennamen in der einschlägigen Forschungsliteratur soweit wie möglich zu vereinfachen, gleichzeitig aber die Lesbarkeit des Textes zu bewahren. Folgende, als Kompromisse zu verstehende Grundregeln gelten daher:

1. Die in den lateinischen und altfranzösischen Quellen überlieferten Namen bekannter historischer Persönlichkeiten werden, in Anlehnung an die Nomenklatur in der Neuedition der Urkunden der Jerusalemer Könige ${ }^{1}$, in einer lokalisierten Variante angegeben, so etwa Guido von Lusignan statt Guy de Lusignan oder Rainald von Châtillon statt Renaud de Châtillon.

2. Arabische und persische Personennamen sowie Fachtermini werden gemäß dem Standardsystem der Deutschen Morgenländischen Gesellschaft (DMG) wiedergegeben. Eine Ausnahme bilden lediglich im deutschen Sprachgebrauch allgemein bekannte Namen und Begriffe, etwa Saladin statt Șalāh ad-Dīn, oder Wesir statt wazìr.

3. Türkische Orts- und Personennamen werden in einer in der Forschungsliteratur gängigen, an das moderne Türkisch angelehnten Form wiedergegeben und gegebenenfalls wichtige Varianten erwähnt, so etwa Qılı̌̌ Arslān oder Gümüštegin (Kumuštakin).

4. Griechische und armenische Personen- und Ortsnamen werden, wie in der Forschungsliteratur üblich, in einer lokalisierten Form wiedergegeben, so etwa Johannes Kinnamos oder Thoros.

5. Für Orts- und Städtenamen gilt:

a. Allgemein bekannte Orte wie Antiochia, Tripolis, Jerusalem, Aleppo oder Damaskus werden in der im deutschen Sprachgebrauch geläufigen, lokalisierten Form angegeben.

b. Weniger bekannte Orte mit arabischem Namen werden nach den Regeln des DMG-Systems angegeben, so etwa Hims oder $A^{\prime} z \bar{a} z$.

c. Bei weniger bekannten Orten, die sowohl lateinische und französische als auch griechische oder arabische Namen besessen haben, wird eine in der

1 Hier zitiert als D/DD Jerus., zur Auflösung der Angabe s. den entsprechenden Eintrag im Quellenund Literaturverzeichnis. 
Forschungsliteratur häufig gebrauchte Form verwendet und gegebenfalls weitere Varianten angegeben. 
